\title{
Corresponsales de guerra en el campo de batalla: un estudio de su relación con militares desde Crimea a Irak
}

\author{
Leire ITURREGUI MARDARAS \\ Universidad del País Vasco UPV/EHU \\ María José CANTAlapiedra GonZÁLEZ \\ Universidad del País Vasco UPV/EHU \\ Leire Moure PeÑín \\ Universidad del País Vasco UPV/EHU \\ Rosa María MARTín SABARÍS \\ Universidad del País Vasco UPV/EHU
}

\begin{abstract}
Resumen:
Hasta la guerra de Crimea todos los elementos que intervenían en una guerra estaban bajo tutela militar, incluido el relato de la misma. La aparición del primer corresponsal de guerra civil y vinculado a un medio supuso la creación de un nuevo frente en zona de operaciones: la gestión de la relación entre periodistas y militares. Esta investigación revisa la interacción entre ambas partes desde Crimea hasta Irak, concluye que la tecnología y el balance militar del conflicto anterior han condicionado esta relación y propone una reflexión sobre el sistema actualmente en vigor.
\end{abstract}

Palabras clave: Corresponsales de guerra; Guerra de Vietnam; Guerra de Irak 2003; sistema de empotrados

\section{War correspondents on the battlefield: an approach to their relationship with the military from Crimea to Iraq}

\begin{abstract}
:
Until the Crimean War all the elements involved in the wars were under military supervision, including the story of them. The burst on the scene of the first civil war correspondent and linked to a medium resulted in the creation of a new front in operations: the management of the relationship between journalists and the military. This research examines this interaction from Crimea until Iraq, it stresses the importance of two factors like technology and the military balance of the previous conflict and it proposes a reflection on their relationship from now on.
\end{abstract}

Keywords: war reporters; Vietnam War; Iraq War 2003; embedded system

\section{Referencia normalizada:}

Iturregui Mardaras, L., Cantalapiedra González, M. J., Moure Peñín, L. y Martín Sabarís, R. M. (2014): Corresponsables de guerra en el campo de batalla: un estudio de su relación con militares desde Crimea a Irak. Historia y Comunicación Social. Vol. 19. Núm. Especial Febrero. Págs. 645-654.

Sumario: 1.Introducción. 2. Metodología. 3. Periodistas y militares en operaciones. 3.1. Vietnam: fin a un siglo de acercamientos. 3.2. Irak 2003 como vuelta al origen: el renacer del periodista 'empotrado'. 4. Conclusiones. 5. Bibliografía 


\section{Introducción}

La aparición en la guerra de Crimea (1854) del primer corresponsal civil, desarmado y contratado por un medio genera un punto de inflexión no sólo en la historia del reporterismo de guerra, sino también en el diseño e implementación de la estrategia militar. Hasta ese momento eran los propios militares quienes elaboraban el relato de lo ocurrido en el campo de batalla, pero en Crimea emerge una nueva figura encargada de mediar entre el frente y la opinión pública: el periodista. William Howard Russell inauguraba una nueva era periodística y asistía al nacimiento de la censura militar como reacción a sus crónicas. A partir de ese momento ejércitos y gobiernos de todo el mundo han diseñado sistemas para gestionar la presencia de periodistas en las operaciones en el exterior y "el corresponsal de guerra - en líneas generales - ha pasado a ser un engranaje más de la gran maquinaria bélica" (Altabella, 1945: 13).

La presente investigación ofrece una revisión de esta relación entre periodistas y militares en operaciones desde la aparición en escena del considerado como primer corresponsal de guerra hasta la actualidad. El trabajo centra la atención en dos momentos clave. Por un lado, en la guerra de Vietnam, donde los reporteros trabajaron sin censuras, con una libertad sin precedentes y en convivencia informal con los militares. Sin embargo, una vez finalizada la guerra, la percepción de los militares de que la cobertura mediática fue la principal causa de la derrota estadounidense supuso la ruptura de la confianza entre ambas partes. El segundo punto de atención se ubica en la guerra de Irak en 2003, donde se recuperó la primera forma de relación entre periodistas y militares, su convivencia, acompañada esta vez de un contrato suscrito por ambas partes. El modelo, conocido como sistema de empotrados o embedded system, fue diseñado por el Departamento de Defensa estadounidense y diez años después se ha consolidado como una de las principales vías para la cobertura de conflictos y como herramienta para acercar ambos bandos. El trabajo completa la revisión histórica incluyendo la experiencia de periodistas españoles que participaron en este sistema durante la guerra de Irak; una información obtenida a través de entrevistas personales.

Finalmente, se propone una reflexión sobre los factores que han condicionado la presencia y el trabajo de periodistas en el frente y sobre cuál puede ser el método que rija a partir de ahora esta tradicionalmente compleja relación entre los dos bandos.

\section{Metodología}

El objetivo principal de la investigación reside en estudiar la evolución de la relación entre reporteros y militares en operaciones desde la guerra de Crimea hasta la última guerra de Irak. De este propósito principal se derivan el resto de los objetivos de la investigación. Por un lado, conocer qué estrategias se han diseñado desde el ámbito militar para controlar la presencia y el trabajo de periodistas en el frente y 
cómo ha sido la respuesta de los profesionales de la información en los principales conflictos en el último siglo y medio. Por otro lado, identificar qué factores han influido históricamente en la implementación de programas para gestionar la relación con periodistas. Finalmente, se pretende elaborar un diagnóstico sobre cómo se rige esta relación entre en la actualidad, para poder esbozar una previsión de cómo se abordaría la presencia de los periodistas en caso de declararse una intervención militar con participación de tropas españolas.

Para elaborar el estudio se han analizado, en primer lugar, las principales obras sobre el reporterismo de guerra que incluyen referencias sobre el objeto de estudio en España. Se ha prestado especial atención a la bibliografía estadounidense, donde la cuestión ha sido abordada por el ámbito académico, el periodístico y el militar. En relación a la última guerra de Irak, con el objetivo de completar la visión recogida en la literatura existente y de conocer de primera mano cuál ha sido la experiencia de los reporteros españoles, se han efectuado entrevistas en profundidad a quienes convivieron con unidades militares. Se ha optado por esta técnica cualitativa por ser considerada como la principal herramienta para "excavar", y se ha empleado en un formato abierto y no estandarizado procurando que la inmensa mayoría de las mismas se celebraran de forma presencial (Taylor y Bogdan, 1987).

\section{Periodistas y militares en operaciones}

Históricamente los militares han controlado todos los elementos que intervenían en las contiendas, incluido el relato de las mismas. Los despachos de guerra tienen su origen en los militares que narraban lo ocurrido en el campo de batalla una vez terminada su participación. Algunos de los nombres que destacaron en esta labor fueron Jenofonte, Julio César o Tucídides. Pero a finales del siglo XVIII la prensa adquiría una creciente importancia; en la guerra de la Independencia en Estados Unidos no hubo periodistas pero comenzaba la preocupación por la visión que ofrecían los medios, incluidas las primeras acusaciones a la prensa de "minar" el trabajo de los militares (Aukofer y Lawrence, 1995: 35). Quienes enviaban sus informaciones seguían siendo militares, hasta 1854, cuando el diario The Times decide enviar a William Howard Russell a la guerra de Crimea. Por primera vez un civil, desarmado y vinculado a un medio daba cuenta de lo que ocurría en el frente.

Desde un comienzo la relación de Russell con los militares fue tensa. Lo acusaron de poner en peligro la seguridad de las tropas y de ofrecer asistencia al enemigo por denunciar la precaria situación de los soldados y el 25 de febrero de 1856 instauraron la prohibición de publicar cualquier información considerada de valor para el contrario y autorizaron la expulsión de quien no cumpliera esa norma: era el comienzo de la censura militar (Knightley, 2004: 17). Cinco años después, durante la Guerra Civil Americana, todas las líneas de telégrafo con destino a Washington fueron intervenidas. La censura constituía una demostración de la importancia que el gobierno 
otorgaba al trabajo de los reporteros y el reconocimiento al papel de la prensa como "una de las claves para mantener el apoyo popular" (Aukofer y Lawrence, 1995: 36).

A finales del siglo XIX España estaba sumida en las guerras de África y comenzaban a conocerse los primeros nombres de reporteros vinculados a medios, como Francisco Peris Mencheta, Gaspar Núñez de Arce, Pedro Antonio de Alarcón Ariza, Rafael Guerrero, Ramón García Rodrigo Nocedal, Ángel Mingüez, Antonio Rodríguez, Luis Morote, Rodrigo Soriano y Barroeta-Aldamar o José Boada y Romeu (Martínez Salazar, 1998: 88-93). Algunos eran militares; como Alarcón, considerado como "precursor de los modernos corresponsales bélicos" y "soldado a las órdenes de Ros de Olano" (Altabella, 1945: 12). Boada y Romeu, primer corresponsal de guerra de La Vanguardia, trabajaba "incrustado" con militares españoles y denunciaba en sus crónicas la existencia de censura: "Me comunican que el ejército me ha anulado un telegrama que daba cuenta de haber cogido los soldados del fuerte Camellos a un chiquillo hebreo portador de pliegos para los rifeños" (García-Planas, 2007: 26). Para conocer el trabajo de la primera corresponsal española, Carmen de Burgos - Colombine -, hubo que esperar a que comenzara el siglo XX.

Durante la primera mitad del siglo XX, marcada por las dos guerras mundiales, se mantiene la convivencia entre militares y periodistas y comienza a controlarse quién asiste al campo de batalla: es el inicio del sistema de acreditaciones. Los corresponsales necesitarían un pase de prensa y un pasaporte; una vez abierto el camino al frente, los periodistas eran asignados a "campos de prensa" y podían acompañar a los militares (Comité para la Protección de Periodistas, 2004). Según Aukofer y Lauwrence fue durante la Segunda Guerra Mundial cuando se alcanzó el máximo nivel de integración entre militares y periodistas: los reporteros vestían uniforme militar y viajaban con las unidades al tiempo que los editores aceptaban la censura como el precio a pagar por salvaguardar la seguridad nacional (1995: 38). Fue también durante esta guerra cuando se crearon algunas oficinas específicas para la censura, entre de ellas, la activada por el presidente de los Estados Unidos Franklin Delano Roolsevelt en 1941 para controlar toda pieza informativa que saliera de Estados Unidos o procediera de cualquier otro país y que empleó a cerca de 15.000 civiles (Hetnar, 2007:19). Paralelamente, la tecnología inauguraba la idea de la guerra contada en directo a través de las retransmisiones de radio. No fueron las únicas novedades: comenzó a experimentarse el sistema de los' pool' o selección de grupos periodistas que acompañarían a las tropas para narrar después a sus compañeros lo ocurrido en el frente, que vería su regulación cuarenta años más tarde.

\subsection{Vietnam fin a un siglo de acercamientos}

La guerra de Vietnam constituye un hito en la historia del periodismo de guerra. Por un lado, como afirma Leguineche, los periodistas trabajaron con "casi plena libertad de movimientos", puesto que "la censura, con más de 700 periodistas acreditados en Saigón, era poco menos que imposible", por lo que los corresponsales se movieron "a sus anchas y gratis". Reconoce, no obstante, que esa "libertad" de la que gozaron en Vietnam "no volvería a repetirse" (Leguineche y Sánchez, 2004: 265-275). Por otro 
lado, la tecnología volvía a determinar el relato de la guerra, marcada por el impacto de la retransmisión de imágenes a través de la televisión.

Ese laissez-faire que reinó en Vietnam comenzó a resquebrajarse a partir de la ofensiva del Tet en 1968 (Hernat, 2007:28), cuando comenzaron a aflorar las primeras diferencias en el relato de la contienda. El gobierno estadounidense y el ejército trataron de trasladar a la opinión pública una visión positiva del desarrollo de la guerra, pero las portadas de los periódicos narraban una realidad radicalmente distinta. Michael Herr, corresponsal en Vietnam, recuerda las acusaciones que los militares lanzaban a los periodistas: "Había oficiales, y muchos soldados aparentemente ingenuos, que creían que de no ser por nosotros ya no habría guerra [...] tarde o temprano, todos oíamos una u otra versión de "Mis marines están ganando esta guerra y ustedes están perdiéndola por nosotros en sus periódicos"' (Herr, 2001: 235). Segú algunas investigaciones americanas el 64\% de los militares acusa a los medios de comunicación de haber perjudicado el esfuerzo militar en esta guerra (Aukofer y Lawrence, 1995: 40). Ciertamente, tras Vietnam la desconfianza selló las relaciones entre periodistas y militares.

A partir de ese momento la relación entre ambos bandos y la libertad de información en zona de operaciones sufrió un giro de $180^{\circ}$. El principal objetivo de los militares se centró en mantener a los periodistas alejados de los combates (Comité para la Protección de Periodistas, 2004). En las Malvinas (1982) los corresponsales no pudieron acceder al campo de batalla sin la colaboración del Ministerio de Defensa británico, lo que generó una situación excepcional para la negociación de las reglas de juego: "Los diecisiete reporteros que finalmente fueron acreditados tuvieron que firmar unos documentos en los que aceptaban la censura de seis "relaciones públicas" del Ministerio. El resultado es que se informó de la guerra tal y como el ejército quería que se hiciera" (Leguineche y Sánchez, 2004: 420). Tres años después, la guerra de Granada (1985) era considerada como uno de los momentos más críticos en las relaciones entre medios y militares: cerca de seiscientos periodistas llegaron al terreno pero prohibieron su entrada hasta pasadas cuarenta y ocho horas (Paul y Kim, 2004: 40). Los reporteros denunciaron el incumplimiento de la Primera Enmienda relativa a la libertad de prensa y se creó una Comisión encargada de diseñar un sistema para próximos conflictos. En 1985 nacía el National Media Pool, que regulaba la selección de un grupo de periodistas que podría tener acceso a las operaciones y se encargaría después de trasladar la información al resto de compañeros. Se estrenaba cuatro años después en Panamá, pero con escaso éxito: los escogidos fueron retenidos y quienes actuaron por libre lograron un mayor acceso a la información.

En 1991 comenzaba la Guerra del Golfo y las negociaciones para decidir cómo gestionar la presencia de periodistas se alargaron durante meses hasta acordar la aplicación de los 'pool'. Algunos estudios cifran en 1.600 periodistas en Arabia Saudí, de los que 186 fueron seleccionados para estos 'pool' (Paul y Kim, 2004: 43). Sin embargo, la falta de acceso a la información generó que muchos decidieran volver a aventurarse de manera independiente. Algunos fueron capturados, otros se retiraron de forma voluntaria o por presiones recibidas de su medio. Sólo dos lograron 
mantenerse en Bagdad en el inicio de la guerra: el estadounidense Peter Arnett, de la CNN, y el español Alfonso Rojo, corresponsal de El Mundo (Rojo, 1995:148-149). De hecho, las imágenes de la $C N N$ constituyeron la principal fuente de información para medios de todo el mundo (Martín Sabarís, 1991: 71) y convirtieron la guerra del Golfo en la primera contienda retransmitida en directo a través de la televisión.

En el balance tras la guerra se reconoció la censura ejercida durante el conflicto y se reconsideró el sistema de relación entre periodistas y militares. Durante ocho meses se trabajó para elaborar un nuevo modelo y el texto acordado, el "Principles for News Media Coverage of DoD Operations", relegaba la opción de los 'pool' a una medida excepcional para el inicio de la intervención y establecía que debía ser disuelto cuanto antes. Además, fundaba un sistema de credenciales, ofrecía acceso a las unidades y recogía el compromiso militar de no intervenir en el trabajo de los periodistas, de transportar a los 'pool' y de procurar a los informadores los medios necesarios siempre que fuera posible (Paul y Kim, 2004: 46). Sin embargo, su aplicación no fue inmediata. En Somalia (1992) los periodistas llegaron antes que los militares; hecho que se repetía dos años después en Haití. A pesar de ello, afloraban ya indicios de cooperación entre ambas partes; en Haití acordaron las normas para trabajar en la zona y algunos reporteros viajaron con militares (Paul y Kim, 2004: 47). Comenzaba, por tanto, una recuperación de la confianza perdida que sería clave para los siguientes conflictos.

En los Balcanes, según el teniente coronel Suevos Barreros "la prensa contaba con toda la libertad habitual en el mundo occidental. Asumiendo sus propios riesgos [...] estaba en casi todas partes" (2003). En Bosnia se utiliza por primera vez el término 'embedded'para referirse a la convivencia entre reporteros y militares: "Los periodistas eran incorporados con unidades en Alemania y viajaron hasta Bosnia para permanecer entre dos y seis semanas [...] la intención era que se familiarizasen con las unidades y soldados" (Bauluz, 2008: 27). Ramón Lobo describe su relación con los militares y aunque afirma que percibían ciertas hostilidades, muestra una notable confianza con ellos, como puede apreciarse en el siguiente diálogo con un coronel:

Antes de partir le murmuré en secreto, casi al oído:

- Coronel: quiero ir dentro de uno de esos blindados que van a dormir en Mostar.

Morales me dijo que no, que yo no era un novio de la muerte y que si me mataban sería su responsabilidad. dad?

- Y si les sigo con mi Lancia sin blindaje, ¿cree que esquivará esa responsabili-

El coronel que tenía el tamaño de Franco me espetó:

- ¡No me jodas, hijo! Espérate hasta mañana... Mañana entras. Te lo prometo. Pero no hagas tonterías, por favor... (Lobo, 1999: 74) 
En Kosovo (1999) no hubo convivencia entre militares y periodistas y hay quien afirma que la distancia entre ambas partes favoreció la difusión de propaganda por parte de Milosevic (Knightley, 2004). Dos años después, la expectativa era alta en Afganistán, pero la prensa fue excluida de esta operación (Paul y Kim, 2004: 51) y los reporteros no tuvieron acceso al terreno. Su entrada a algunas zonas fue vetada y justificada porque los militares estadounidenses tenían la "obligación de controlar el campo de batalla" (Katovsky y Carlson, 2004: 206). En 2003, durante la invasión de Irak, se recupera la más antigua fórmula para la organización de la prensa, su convivencia con militares, aunque eso sí, con importantes novedades.

\subsection{Irak 2003 como vuelta al origen: el renacer del periodista empotrado}

En Washington se debatió durante meses cómo regular la presencia de periodistas en Irak. Finalmente, la principal novedad fue el diseño del 'embedded system' o 'sistema de empotrados' (Wright y Harkey, 2004): una propuesta que retomaba y regulaba como nunca antes la relación original entre periodistas y militares en operaciones, su convivencia, a través de las normas recogidas en el "Public Affairs Guidance on Embedding Media During Possible Future Operations/Deployments in the U.S. Central Commands Area of Reponsibility". El documento describe que la política del Departamento de Defensa estadounidense para la cobertura de operaciones militares consistiría "en un largo y mínimamente restrictivo acceso a las fuerzas estadounidenses de tierra, mar y aire, a través del empotramiento (embedding)". Justifican la medida por considerar que es necesario "contar la historia de los hechos - buena o mala - antes de que otros bombardeen a los medios con desinformación y distorsiones". Para ello, proponen una organización militar orientada a facilitar el acceso a profesionales de medios tanto nacionales como internacionales para asignar o "empotrar" estos reporteros, que vivirán, trabajarán y viajarán como parte de esas unidades militares (Departamento de Defensa, 2003). Las normas prohíben informar sobre futuras misiones, resultados concretos de operaciones, poner en riesgo la "seguridad operacional", dar cuenta de números concretos de tropas y equipamientos militares y viajar en sus propios vehículos. Quien no respetara alguno de los puntos sería expulsado del sistema.

Un total de 692 periodistas trabajaron empotrados en unidades militares durante la guerra de Irak. Cerca de 300 organizaciones, un $20 \%$ extranjeras, demandaron tener acceso al sistema, entre ellas, la cadena árabe Al-Jazeera o la agencia de prensa china Xinhua (Bushel y Cunningham, 2003). Tres de cada cuatro empotrados pertenecían a medios estadounidenses; un total de 514. El resto trabajaba para medios de 27 países, liderados por el Reino Unido, principal aliado durante la guerra de Irak, que sumó 61 profesionales empotrados, seguido de Francia (25 empotrados), Japón (19) y Alemania (15).

España ocupaba la séptima posición con siete empotrados: cinco periodistas y dos cámaras. Fueron una mujer, Mercedes Gallego, y seis hombres. Uno de ellos, Julio Anguita Parrado, falleció en un ataque cerca de Bagdad el 7 de abril de 2003, junto a otro periodista alemán y dos soldados estadounidenses. Gallego fue la enviada del 
Grupo Correo -ahora Vocento-; Alfonso Bauluz el de la Agencia EFE; José Antonio Guardiola fue el reportero enviado por Televisión Española y con el cámara Evaristo Canete trabajó asignado a unidades del ejército británico; la cadena pública contó con otros dos profesionales empotrados con militares estadounidenses, el periodista Ángel Orte y el cámara Miguel Ángel De la Fuente, quien durante dos semanas se quedó sólo en la unidad y ejerció de reportero y cámara al mismo tiempo.

La valoración general es positiva. Bauluz calificaba su relación con los marines de "muy buena", aunque admitía que el hecho de que muchos fueran hispanos contribuyó a ello. Guardiola y Canete lograron también una buena sintonía con el ejército -británico-; Guardiola definía su comportamiento como "fantástico, impecable" y alababa su organización. Ángel Orte y Miguel Ángel De la Fuente consideraron también que la relación con los militares fue buena; este último, que afrontó en solitario más de la mitad de la aventura, declaraba: "Cuando me quedé sólo, tenía un buen rollo especial; venían los oficiales a buscarme para cenar, para desayunar... y solíamos hablar mucho". Una percepción bien distinta mantiene Gallego, quien en la entrevista describía la convivencia como especialmente complicada: "La relación con los militares era muy difícil. Primero, porque nosotros no estábamos sujetos a su disciplina. Segundo, porque no entendían la naturaleza de nuestro trabajo. Y tercero, porque siempre nos veían como una peligrosa filtración a punto de ocurrir que comprometería su seguridad y podría costarles la vida a ellos y a sus compañeros". Y subraya la dificultad extra que entraña ser mujer en este contexto: "Como empotradas nos encontramos con el comportamiento errático y arbitrario de soldados que no saben tratar con mujeres y que se sienten amenazados en nuestra presencia".

Diez años después de la guerra de Irak, el sistema de empotrados se ha consolidado como fórmula para la cobertura de conflictos. El ejército estadounidense y la OTAN mantienen un procedimiento permanentemente abierto y de respuesta inmediata para facilitar el trabajo con las unidades en operaciones a periodistas de todo el mundo: basta con solicitar a través de la web la asignación a una unidad militar en operaciones en las que participan y suscribir un documento que recoge las normas que deben respetar. Tras analizar la solicitud, se recibe una respuesta con los datos necesarios: cuándo y dónde comenzará el empotramiento con qué unidad de qué ejército.

\section{Conclusiones}

Las principales fórmulas para regular el acceso de la prensa al campo de batalla han sido diseñadas y activadas en su inmensa mayoría por los Estados Unidos. En las contiendas más mediáticas del siglo XX ha sido el Pentágono quien ha negociado y establecido los distintos procedimientos $\mathrm{y}$, especialmente, aquéllos que han marcado un antes y un después en cada una de las fases vividas en relación a la organización de la prensa y su relación con militares. La extensa documentación existente sobre esta cuestión en el país norteamericano constituye, a su vez, un factor revelador de la 
importancia y de la fuerte tradición del país en la materia. El sistema de empotrados es, por tanto, un paso más en el camino que viene recorriendo desde que en la Guerra Civil americana el General William Tecumseh Sherman estableciese ese vínculo directo entre censura y victoria militar.

Tras una revisión histórica, puede concluirse que desde la guerra de Crimea, dos elementos han condicionado especialmente la presencia de periodistas en el campo de batalla: la experiencia vivida en el último conflicto y las conclusiones que del ámbito militar se extrajeran del mismo y el desarrollo de la tecnología. Desde el momento en el que nace la figura del corresponsal de guerra, la prisa por llegar en primer lugar ha marcado su trabajo, y si los pioneros trataban de hacer llegar sus despachos sobre lomos de los caballos más rápidos pronto conocerían nuevas dimensiones en la transmisión de información: el telégrafo, el teléfono, la radio, la televisión... Cada salto tecnológico ha condicionado la cobertura de las guerras y los mecanismos de censura han exigido un nivel de sofisticación a la altura de la técnica del momento hasta que el control ha resultado imposible. El exponencial avance de la tecnología ha obligado al ámbito militar a recuperar los modos de relación original con periodistas en el campo de batalla: en la actualidad, por encima de normas y acuerdos previos, el principio de confianza se erige en el principal mecanismo que rige esta relación.

Por otro lado, la experiencia de conflictos previos o su balance militar ha constituido, desde la guerra de Crimea, el punto de inicio para regular la relación entre periodistas y militares de siguientes contiendas. A pesar de la desconfianza inicial, desde finales del siglo XIX hasta mediados del XX la libertad de los periodistas y la confianza entre ambas partes fue creciendo hasta tocar techo en Vietnam. La percepción por parte de los militares de que la prensa jugó un papel determinante en la derrota marcó un punto de inflexión y segó las libertades de los periodistas en zona de operaciones, negando, incluso, su acceso al terreno en los próximos conflictos. Desde entonces, distintos sistemas se han diseñado e implementado para lograr un acercamiento, hasta la última guerra de Irak, donde se recupera la convivencia entre periodistas y militares, regulada en esta ocasión por un contrato firmado. Un modelo consolidado en la actualidad y validado por ambas partes como presente y futura vía para la cobertura de conflictos.

\section{Bibliografía}

ALTABELlA, J. (1945). Corresponsales de guerra. Su historia y su actuación. De Jenofonte a Knickerbocker pasando por Peris Mencheta. Madrid: Febo.

AUKOFER, F.; LAWRENCE, W. P. (1995). America's Team. The Odd Couple. A Report on the Relationship Between the Media and the Military. Nashville: Freedom Forum First Amendment Center.

BAULUZ, A. (2008). Periodistas con control remoto. Trabajo fin de Master en 'Periodismo y Divulgación'. Madrid: Universidad Complutense de Madrid. 
BUSHEL, A.; CUNNINGHAM, B. (2003). "Suddenly the Pentagon Grants Access to the Action But the Devil's in the Details". En: Columbia Journalism Review, $\mathrm{n}^{\circ}$ 2. Disponible en: http://www.cjr.org/year/03/2/embed.asp

Comité para la Protección de Periodistas (2004). En Cobertura: Una guía para informar en situaciones de peligro. Nueva York: Comité para la Protección de Periodistas. Disponible en: http://www.cpj.org/regions_05/ americas_05/Safety_Guide_Sp.pdf [20-07-2013]

Departamento de Defensa (2003). Public Affairs Guidance (PAG) on Embedding Media During Possible Future Operations/Deployments in the U.S. Central Commands (CENTCOM) Area of Responsibility (AOR). Disponible en: www. defense.gov/news/feb2003/d20030228pag.pdf [10-05-2013]

GARCIA-PLANAS, P. (2007). La revancha del reportero. Tras las huellas de siete grandes corresponsales de guerra. Barcelona: Diëresis.

GUILLAMET, J. (2012). "Joaquín Mola y Martínez y los primeros corresponsales de guerra". En: Textual, Visual \& Media, n 5, pp.225-238.

HERR, M. (1968). Despachos de Guerra. Barcelona: Anagrama.

HETNAR, N. (2007). From the First World War to the 2003 Iraq War. The American mainstream media coverage of an international conflict. Poznán.

KATOVSKY, B.; CARLSON, T. (2004). Embedded: The Media At War in Iraq. Connecticut: The Lyon Press.

KNIGHTLEY, P. (2004). The First Casualty. The War Correspondent as Hero and Myth-Maker from the Crimea to Iraq. Baltimore and London: The Johns Hopkins University Press.

LEGUINECHE, M.; SÁNCHEZ, G. (2004). Los ojos de la guerra. Barcelona: Random House Mondadori.

LOBO, R. (1999). El héroe inexistente. Madrid: Grupo Santillana Ediciones.

MARTÍN SABARÍS, R.M. (1991). "Euskal Telebista, Golkoko Gerran”. En: Uztaro, $\mathrm{n}^{\circ} 3$, pp.69-75.

MARTÍNEZ SALAZAR, Á. (1998). "Los primeros corresponsales de guerra españoles". En: Historia 16, n²72, pp. 88-9.

PAUL, C.; KIM, J. J. (2004). Reporters on the Battlefield. The Embedded Press System in Historical Context. California: RAND Corporation.

ROJO, A. (1995). Reportero de guerra. La historia, los secretos, los vicios y las virtudes de los corresponsales. Barcelona: Planeta.

SUEVOS BARRERO, R. (2003). "Algunas Reflexiones sobre la Comunicación Pública en Operaciones". En: Ejército de tierra español. Revista de las armas y de los servicios, $\mathrm{n}^{\circ} 748$, Junio.

TAYLOR, S.I.; BOGDAN, R. (1987). Introducción a los métodos cualitativos de investigación. Barcelona: Paidós.

WRIGHT, R.K.; HARKEY, W.H. (2004). Assessment of the DoD Embedded Media Program. Institute For Defense Analyses. Disponible en: www.dtic.mil/cgi-bin/ GetTRDoc?AD=ADA441268 [12.05.2013] 